\title{
An Editor-in-Chief's Farewell
}

As of July 1, Acta Haematologica will have a new Editor-in-Chief and Prof. Pia Raanani will replace me. My term was very long, 25 years as the head of the editorial board. During this period, we moved from the 20th to the 21st century and from an era of exclusively clinical hematology to contemporary hematology with its translational profile. The journal went from typewritten manuscripts and post office delivery to paperless submissions, computerized reviews, and editorial decisions. During all these transitions and technological progress, I did my best to keep the journal clinically oriented with practicing clinical hematologists as the target readership. Our rejection rate is about $60 \%$ and the leading country of origin is by far China, where $30 \%$ of the submitted articles are from.

As everyone in the discipline knows, there is a huge selection of hematology journals. There is fierce competition with the giants in the field, many of them backed by national societies. In these conditions, I have tried to maintain the journal's high standards, which is reflected in the high rejection rate.

During my entire term, I have enjoyed complete academic freedom without any outside interference. For this I am greatly indebted to the publisher and particularly to Mr. Thomas Karger, who entrusted the journal to my hands for such a long period.

I would like to thank the efficient support from the editorial board members in Basel, the production staff, and the countless reviewers. With a wish of success to the new Editor-in-Chief, I bid farewell to all.

Isaac Ben-Bassat, MD

Prof. Emeritus of Hematology 